\title{
Interganglionic Axonal Transport of Neuropeptides in Aplysia
}

\author{
Philip E. Lloyd \\ Department of Pharmacological and Physiological Sciences and Committee on Neurobiology, University of Chicago, \\ Chicago, Illinois 60637
}

\begin{abstract}
The transport of neuropeptides between central ganglia was studied in Aplysia. Peptide transport was determined by incubating ganglia with ${ }^{35} \mathrm{~S}$-methionine and measuring the appearance of labeled peptides in connected ganglia. Selected interganglionic connectives were left intact and passed through a diffusion barrier separating the ganglia. Labeled peptides transported between ganglia included FMRFamide, myomodulin, and pedal peptide. Each of these peptides has been shown to be physiologically active in Aplysia. In addition to these previously characterized neuropeptides, a number of other as yet uncharacterized labeled peptides were also transported. All the peptides were transported by fast axonal transport as judged by the distance transported and/or the sensitivity to colchicine. Overall, FMRFamide and several unidentified peptides were the predominant transported peptides. However, the nature and amount of the peptides transported differed for each ganglia. These results support the proposition that the labeled peptides have transmitterlike actions and suggest that there are a number of neuropeptides that are likely to have central actions that have not yet been characterized in Aplysia.
\end{abstract}

The present study was directed towards 3 objectives. The first was to identify previously sequenced neuropeptides that were transported between ganglia that make up the CNS of Aplysia. The second goal was to use axonal transport as a means to identify new neuropeptides that may have transmitterlike roles. Although the amino acid sequences of a number of neuropeptides from Aplysia have been determined, these peptides were generally chosen for study because they are synthesized in large quantities either in very large individual neurons or in homogeneous cell groups, or they may be particularly potent in a bioassay. Many physiologieally important neuropeptides may not fall into these categories and therefore resist identification. Other approaches to peptide identification such as axonal transport may reveal the existence of these peptides. The third longterm objective is to identify presynaptic peptidergic neurons that may form synapses in the ganglia they innervate.

The present study is a continuation of a series designed to identify peptide transmitters on the basis of fast axonal trans-

\footnotetext{
Received Jan. 10, 1989; revised Mar. 2, 1989; accepted Mar. 3, 1989.

I thank C. Connolly and C. White for expert assistance, K. R. Weiss for gifts of synthetic buccalin and myomodulin, and W. Pearson and $\mathrm{M}$. Whim for critical reading of the manuscript. This work was supported by NIH NS 23569 and Whitehall Foundation grants.

Correspondence should be addressed to Philip E. Lloyd, Department of Pharmacological and Physiological Sciences and Committee on Neurobiology, University of Chicago, 947 East 58th, Chicago, IL 60637.

Copyright (c) 1989 Society for Neuroscience 0270-6474/89/093243-07\$02.00/0
}

port. The first study in this series identified peptides that were transported from the buccal ganglia to feeding muscles (Lloyd, 1988). Each of these peptides has now been shown to be biologically active at these muscles and to be synthesized selectively in individual neurons (Lloyd et al., 1984; Richmond et al., 1986; Weiss et al., 1986; Cropper et al., 1987a, b, 1988). In a second study, axonal transport of a peptide from the pedal ganglia to the periphery provided critical evidence that pedal peptide (Pep) was a transmitterlike peptide (Pearson and Lloyd, 1989). Pcp has now been shown to be widely distributed in neurons and fibers in the CNS and periphery and to have central and peripheral biological actions (Lloyd and Connolly, 1989; P. E.Lloyd, unpublished observations). In the present study, this procedure was used to examine transport of peptides between central ganglia. The study was restricted to peptides that contain methionine residues. The results indicate that at least 5 identified peptides and a number of unidentified methionine-containing peptides were transported between ganglia. The identified peptides were FMRFamide (Fa; Price and Greenberg, 1977), myomodulin (Mm; Cropper et al., 1987b), pedal peptide (Pep, Lloyd and Connolly, 1989), and the small cardioactive peptides (SCPs; Morris et al., 1982; Lloyd et al., 1987b). Each of these peptides has been shown to have electrophysiological effects on central neurons. The pattern of peptides transported between ganglia was specific to the individual ganglia labeled and to the target ganglia. Several of the unidentified peptides were transported in large quantities over long distances and have now become prime candidates for purification and sequencing.

\section{Materials and Methods}

Animals. Aplysia californica (Marinus; $150-250 \mathrm{gm}$ ) were kept in running seawater tanks at $15^{\circ} \mathrm{C}$ and fed seaweed every $3-4 \mathrm{~d}$. Animals were immobilized with an injection of isotonic $\mathrm{MgCl}_{2}$ equal to $25 \%$ of their body weight, and ganglia with intact connectives and commissures were removed (Fig. 1).

Transport experiments. Ganglia complexes were placed in transport dishes containing $25 \%$ isotonic $\mathrm{MgCl}_{2}: 75 \%$ ASW (460 mM NaCl, 10 $\mathrm{mm} \mathrm{KCl}, 11 \mathrm{mM} \mathrm{CaCl}_{2}, 55 \mathrm{mM} \mathrm{MgCl}_{2}, 5 \mathrm{~mm} \mathrm{NaHCO}_{3}$, pH 7.8). Transport dishes were $150 \mathrm{ml}$ in volume and had Sylgard bases into which vertical polypropylene cylinders were imbedded. These cylinders had 1-mm-wide vertical slits to allow passage of the connectives. The slits were occluded with Vaseline, and the source ganglia were placed in the cylinders with intact connectives running through the Vaseline gap. Extra Vaseline was added to reseal the gap. The solution in the large outside chamber was then changed to a solution with the following composition: $25 \%$ Aplysia blood, $75 \%$ ASW, $0.01 \%$ glucose, antibiotics (penicillin, $25 \mathrm{units} / \mathrm{ml}$; streptomycin, $25 \mu \mathrm{g} / \mathrm{ml}$ ), 0.01\% 2-mercaptoethanol, and $100 \mu \mathrm{M}$ cold methionine. The inside chamber was changed to the following solution: $50 \%$ Aplysia blood, $50 \%$ ASW, glucose, antibiotics, 2-mercaptoethanol as above, and $0.5 \mathrm{mCi} / \mathrm{ml}^{35} S$-methionine (Amersham; stabilized with $0.1 \% 2$-mercaptoethanol and $15 \mathrm{~mm}$ pyridine, 3,4 dicarboxylic acid). After a 24 -hr labeling period at $15^{\circ} \mathrm{C}$, the solutions in both inner and outer chambers were replaced with a chase 


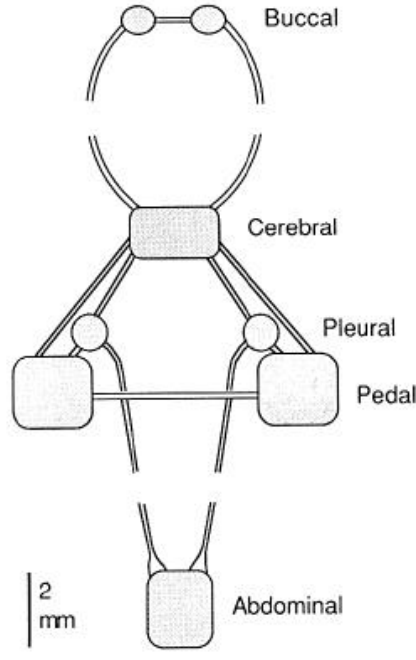

Figure 1. Anatomy of the 5 major ganglia that make up the CNS of Aplysia. Distances between ganglia are those observed in an extended animal of the size used in these experiments $(\sim 200 \mathrm{gm})$. The buccalcerebral connective is about $1 \mathrm{~cm}$, and the pleural-abdominal connective $6 \mathrm{~cm}$, in length. The cell body and neuropil regions of each ganglion are shaded. All ganglia and connectives are surrounded by thick muscular connective tissue.

solution consisting of ASW, glucose, antibiotics, 2-mercaptoethanol as above, and $1 \mathrm{~mm}$ methionine. All solutions were sterilized $(0.2 \mu \mathrm{m}$ filtered) immediately prior to use. For the chase, the solution in the inner chamber was turned over $\sim 20$ times during $1 \mathrm{hr}$, while the solution in the outer chamber was changed once. Chase periods of $24 \mathrm{hr}$ were used. In previous studies in Aplysia, peptide transport rates as high as $100 \mathrm{~mm} / \mathrm{d}$ have been observed under similar label and chase conditions (Pearson and Lloyd, 1989). Thus, the total label-chase period of $2 \mathrm{~d}$ is more than sufficient to permit peptide transport between the most widely separated ganglia ( $\sim 70 \mathrm{~mm}$; see Fig. 1). At least 3 transport and 3 control (see below) experiments were done for each source ganglion. Additional experiments were done if the transported peptide profile was complex (i.e., Fig. 3) or if additional labeled peptides were needed for further characterization.

Radioactivity in the inner and outer chambers were monitored by liquid scintillation counting of small aliquots. At the end of the label periods, the ratio of $\mathrm{cpm} / \mathrm{ml}$ in the inner chamber:outer chamber was $4115 \pm 544$ (SE) for 42 preparations. In several experiments, $10 \mathrm{~mm}$ colchicine (Sigma) was added to both the inner and outer chambers throughout the label and chase periods (see below).

Analyses of ${ }^{35} S$-methionine-labeled peptides in target ganglia. At the end of the chase periods, target ganglia were removed and pinned in ice-cold $25 \%$ isotonic $\mathrm{MgCl}_{2}: 75 \% \mathrm{ASW}$. This solution was replaced with ice-cold 50\% propylene glycol:50\% ASW to facilitate dissection, and the connective tissue sheath surrounding the ganglia was removed. The ganglia which consisted of the cell bodies and neuropil were replaced in homogenizers containing $500 \mu 10.02 \mathrm{M}$ trifluoracetic acid (TFA) and heated to $100^{\circ} \mathrm{C}$ for $10 \mathrm{~min}$. The TFA solution was spiked with $10^{-5} \mathrm{M}$ FMRFamide, $\mathrm{SCP}_{\mathrm{A}}$ and $\mathrm{SCP}_{\mathrm{B}}$ (Peninsula), and usually Pep (Applied Biosystems). After cooling, the ganglia were homogenized, centrifuged at $10,000 \times g$ for $10 \mathrm{~min}$, and the supernatant filtered (Gelman LC13 $0.45 \mu \mathrm{m}$ ) before HPLC.

Two types of controls were carried out. When ganglia were separated by long connectives ( $>10 \mathrm{~mm}$ ), only small amounts of unincorporated ${ }^{35} \mathrm{~S}$-methionine diffused along the connective to target ganglia, and the primary control was for label that had leaked into the outer bath. This control consisted of pinning both the source and target control ganglia from another animal in the outer chamber near the experimental target ganglia. When ganglia were separated by shorter distances, there was significant diffusion of ${ }^{35} \mathrm{~S}$-methionine along connectives to the target ganglia. In these experiments, the control was to compare experiments done in the absence and presence of $10 \mathrm{~mm}$ colchicine, which blocks transport but not synthesis of neuropeptides in Aplysia (e.g., Lloyd et al., 1987a; Lloyd, 1988). At the end of the experiments, control target ganglia were processed in parallel with the experimental target ganglia and run on reverse phase (RP)-HPLC. With the exception of the pedal ganglia, no peptide peaks were observed in any of the control ganglia. Synthesis of Pep was usually observed in control pedal ganglia. This is a reflection of the very high rates of Pep synthesis in this ganglia (Lloyd and Connolly, 1989).

RP-HPLC was carried out on a $0.46 \times 22 \mathrm{~cm}$ Brownlee RP-300 C8 column with a guard column. The first mode of HPLC used $0.01 \mathrm{~m}$ TFA as a counterion and a gradient from $95 \% \mathrm{H}_{2} \mathrm{O}, 5 \% \mathrm{CH}_{3} \mathrm{CN}$ to $47 \%$ $\mathrm{H}_{2} \mathrm{O}, 53 \% \mathrm{CH}_{3} \mathrm{CN}$ in $20 \mathrm{~min}$ at a flow rate of $2 \mathrm{ml} / \mathrm{min}$. In some experiments, the same gradient was run over $40 \mathrm{~min}$ at $1 \mathrm{ml} / \mathrm{min}$. Injections were $600 \mu \mathrm{l} 0.02 \mathrm{M} \mathrm{TFA}$ in $\mathrm{H}_{2} \mathrm{O}$. Aliquots of fractions from these runs were counted, and the remainder of the fractions of interest were dried and run on the same column with $0.01 \mathrm{M}$ heptafluorobutyric acid (HFBA) replacing the TFA. The standard HFBA gradient was comprised of 3 linear segments with different slopes. The first segment was from $79 \% \mathrm{H}_{2} \mathrm{O}, 21 \% \mathrm{CH}_{3} \mathrm{CN}$ to $76 \% \mathrm{H}_{2} \mathrm{O}, 24 \% \mathrm{CH}_{3} \mathrm{CN}$ in 2 min followed by a segment from $76 \% \mathrm{H}_{2} \mathrm{O}, 24 \% \mathrm{CH}_{3} \mathrm{CN}$ to $72 \% \mathrm{H}_{2} \mathrm{O}, 28 \%$ $\mathrm{CH}_{3} \mathrm{CN}$ in $12 \mathrm{~min}$. The final segment was from $72 \% \mathrm{H}_{2} \mathrm{O}, 28 \% \mathrm{CH}_{3} \mathrm{CN}$ to $65 \% \mathrm{H}_{2} \mathrm{O}, 35 \% \mathrm{CH}_{3} \mathrm{CN}$. The flow rate was $2 \mathrm{ml} / \mathrm{min}$ and injections were in $200 \mu \mathrm{l} 0.02 \mathrm{M}$ HFBA in $\mathrm{H}_{2} \mathrm{O}$. Entire fractions from these runs were counted. Unidentified peptides that were transported between the cerebral and the pedal and abdominal ganglia (Fig. 4; peaks 2 and 3) were analyzed with a modified HFBA gradient: $82 \% \mathrm{H}_{2} \mathrm{O}, 18 \% \mathrm{CH}_{3} \mathrm{CN}$ to $34 \% \mathrm{H}_{2} \mathrm{O}, 66 \% \mathrm{CH}_{3} \mathrm{CN}$ in $20 \mathrm{~min}$ at a flow rate of $2 \mathrm{ml} / \mathrm{min}$. These peaks were also analyzed by ion-exchange (IE) HPLC using a Brownlee $0.46 \times 10 \mathrm{~cm}$ Aquapore CX-300 column and a gradient from $10 \mathrm{~mm}$ triethylamine acetate (TEA Ac) to $300 \mathrm{~mm}$ TEA Ac in $15 \mathrm{~min}$ at a flow rate of $2 \mathrm{ml} / \mathrm{min}$. All IE-HPLC solutions contained $10 \% \mathrm{CH}_{3} \mathrm{CN}$. The retention times of synthetic peptides were determined by absorbance at $215 \mathrm{~nm}$ (RP-HPLC) or $260 \mathrm{~nm}$ (IE-HPLC).

\section{Results}

A diagram of the principal ganglia making up the CNS of Aplysia is shown in Figure 1. The interganglionic distances indicated were similar to those observed in an extended animal of the size used in this study. When the nervous system was removed from the animal, the muscular connective tissue sheath surrounding the connectives gradually contracted, causing the inner axonal core of the connectives to coil. Thus, even though the connectives appeared shorter, the axonal lengths remained as indicated in Figure 1.

Transport of peptides between ganglia was monitored by placing individual ganglia in a chamber containing ${ }^{35} \mathrm{~S}$-methionine and running selected connectives through a Vaseline gap to a large outer chamber containing the target ganglia. After label and chase periods, target ganglia were desheathed, and the neuropil and cell body region of the ganglia were extracted and run on RP-HPLC. The ganglia were desheathed because the sheath contained nerve trunks in which peripherally transported peptides might accumulate, and these experiments were directed towards identifying peptides that might be transported into synapses in the target ganglia. Although the total amount of transported labeled peptides varied considerably between experiments, the pattern of peptides transported between ganglia was very reproducible (e.g., Fig. 3). Variations in the level of amino acids incorporated into peptides between preparations has been observed previously (Lloyd, 1988) and presumably reflects differences in endogenous pools of the amino acids or differences in the actual rates of translation and peptide processing.

\section{Transport from the abdominal ganglia}

Labeled peptides were transported from the abdominal ganglia to the pleural, pedal, and cerebral ganglia but not to the buccal ganglia (Table 1). In each case, the major transported labeled peptide was FMRFamide. Transport of FMRFamide to the pleural ganglia was particularly marked with the pedal and ce- 
Table 1. Summary of interganglionic transport of methionine-labeled peptides in Aplysia

\begin{tabular}{clll}
$\begin{array}{l}\text { Source } \\
\text { ganglia }\end{array}$ & Target ganglia & $\begin{array}{l}\text { Identified } \\
\text { peptides }\end{array}$ & $\begin{array}{l}\text { Number } \\
\text { of } \\
\text { unidentified } \\
\text { peaks }^{a}\end{array}$ \\
\hline Buccal & Cerebral & $\begin{array}{l}\text { Fa, Mm } \\
\text { Pep, SCPs }\end{array}$ & 7 \\
Cerebral & Buccal $^{b}$ & $\mathrm{Mm}$ & 2 \\
& Pleural & Fa & 1 \\
& Pedal & Fa & 3 \\
Pedal- & Abdominal & Fa & 3 \\
pleural & Cerebral & Fa, Pep & 1 \\
Abdominal & Abdominal & Fa & 1 \\
& Cerebral & Fa & 2 \\
& Pleural & Fa & 0 \\
& Pedal & Fa & 2
\end{tabular}

Fa, FMRFamide; Mm, myomodulin, Pep, pedal peptide; SCP, small cardioactive peptide.

a To keep this number manageable, only discrete peptide peaks that were reproducibly observed and had at least $20 \%$ of the $\mathrm{cpm}$ found in the dominant peak transported in the same experiment were included. Note that in some cases, these peaks were not analyzed further, so each peak may be made up of several peptides.

${ }^{b}$ From Lloyd (1988).

rebral ganglia receiving 10-fold lower amounts (Fig. 2). Other labeled peaks with less activity were also observed in each of these ganglia but did not coelute with any of our peptide standards. Note that labeled Pep was also observed in the control pedal ganglia. This synthesis of Pep from leaked labeled methionine was commonly observed (also see Fig. 5) and presumably reflects the extraordinary rates of Pep synthesis and peripheral transport from the pedal ganglia (Lloyd and Connolly, 1989; Pearson and Lloyd, 1989). Significant synthesis of labeled peptides was not observed in other control ganglia.

A giant FMRFamide-containing neuron termed R2 is located in the abdominal ganglia and sends an axon via the right connective to the pleural, pedal, and cerebral ganglia and out many peripheral nerves (Rayport and Kandel, 1980; Brown et al., 1985). It was possible that much of the observed FMRFamide transport was in the axon of R2. To test this, transport was measured in preparations in which the right and left pedal/ pleural ganglia were separated at the beginning of the experiment by cutting the pedal-pedal commissure and cutting through the center of the cerebral ganglia (Fig. 1). Abdominal ganglia with both abdominal-pleural connectives intact were then placed in the label chamber. The cerebral ganglia were damaged in these experiments, so only transport to the pleural and pedal ganglia was analyzed. The ratios of labeled FMRFamide transported via the right connective compared with the left connective was $10.7 \pm 6.3(\mathrm{SD} ; n=5)$ for the pedal ganglia but only $1.4 \pm 1.5$ for the pleural ganglia. Thus, most of the FMRFamide transport to the pedal ganglia was via the right connective and may have been in the axon of $\mathrm{R} 2$ but transport to the pleural ganglia was nearly symmetrical in the 2 connectives, suggesting that other FMRFamide-containing axons must also be present in the left connective.

\section{Transport from the buccal ganglia}

In these experiments, the buccal ganglia were placed in the label chamber, and both buccal-cerebral connectives were run through
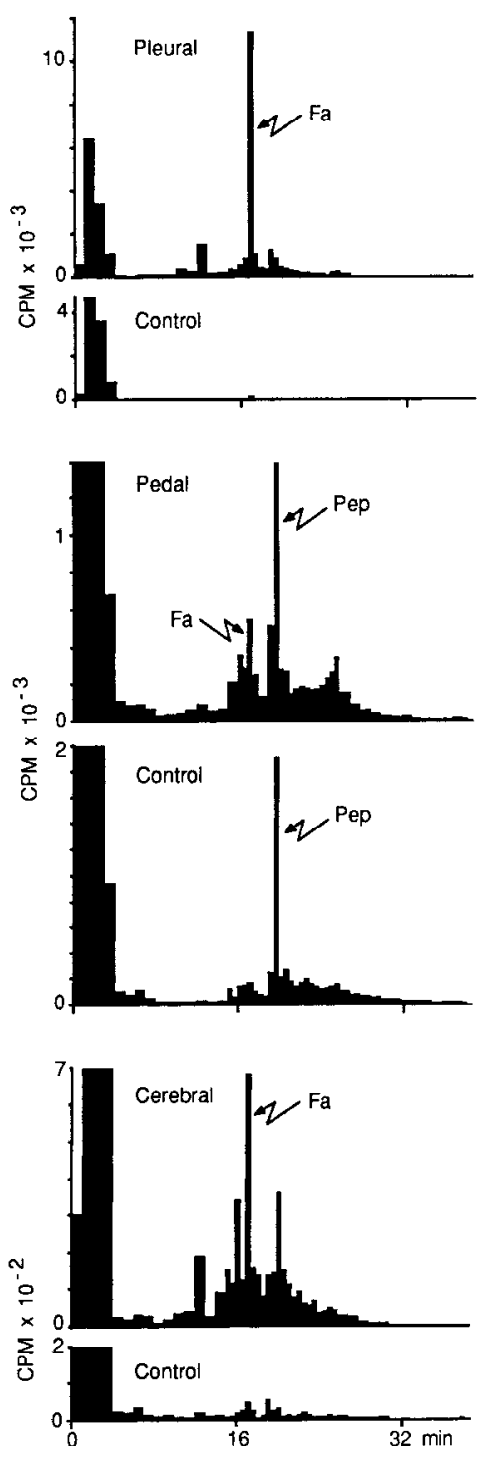

Figure 2. Transport of labeled peptides from the abdominal ganglia to the pleural, pedal, and cerebral ganglia. RP-HPLC of target ganglia extracts with TFA as a counterion. Control ganglia were pinned in the same outer chamber as the experimental ganglia but the abdominal ganglia were not labeled. Aliquots of the peaks marked $F a$ were run on RP-HPLC with HFBA as a counterion and the percentage of $\mathrm{cpm}$ that coeluted with synthetic FMRFamide was $85 \%$ for the pleural ganglia, $86 \%$ for the pedal ganglia, and $90 \%$ for the cerebral ganglia. Note that both the control and experimental pedal ganglia contained nearly equal amounts of labeled Pep, indicating that Pep was not transported but was synthesized in the pedal ganglia itself. Other labeled peaks have not been identified. This experiment is representative of an additional 2 experiments. The large peaks of label with short retention times in this and subsequent figures was primarily unincorporated methionine. This gradient was run with a flow rate of $1 \mathrm{ml} / \mathrm{min}$ compared with $2 \mathrm{ml} / \mathrm{min}$ in subsequent figures.

the Vaseline gap to the cerebral ganglia with all connections to the remaining ganglia intact. However, transport of labeled peptides was only observed to the cerebral ganglia (Table 1). The pattern of labeled peptides was complex, with 6 discrete peaks and several broad, less defined peaks. Nearly identical patterns were observed in each of 6 preparations ( 2 examples are shown in Fig. 3). Aliquots from 2 peaks that had retention times similar to known peptides were run on a second mode of RP-HPLC using HFBA as a counterion (Fig. 3). The labeled peptides in 
Figure 3. Transport of labeled peptides from the buccal ganglia to the cerebral ganglia. $A$ and $B$, Two examples of the RP-HPLC (TFA) of cerebral ganglia from different experiments. Control ganglia had $<65 \mathrm{cpm}$ in any fraction eluting with a retention time later than $3 \mathrm{~min}$. Four additional experiments produced nearly identical patterns. Peak\#1, Aliquots of peak 1 were combined from $A$ and $B$ and run with HFBA as a counterion. Peak \#2, Aliquots of peak 2 were combined from $A$ and $B$ and run with HFBA as a counterion.
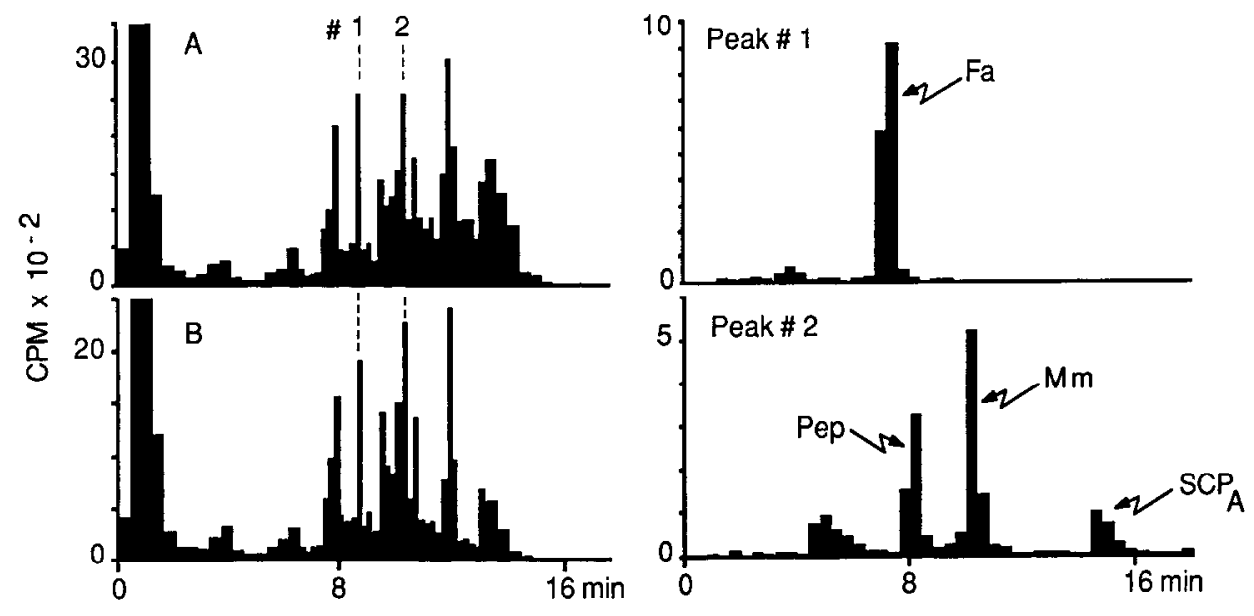

one peak had an identical retention time with FMRFamide, while those of another peak had the same retention times as myomodulin, $\mathrm{SCP}_{\mathrm{A}}$, and Pep. It is likely that a small amount of $\mathrm{SCP}_{\mathrm{B}}$ was also transported as the 2 SCPs are always found together, presumably because they are processed from the same precursor (Mahon et al., 1985). The other peaks were not identified and represent uncharacterized potential peptide transmitters.

\section{Transport from the cerebral ganglia}

The transport of large quantities of labeled myomodulin from the cerebral ganglia to the buccal ganglia has been reported previously (Lloyd, 1988). In the present study, we found that FMRFamide was transported from the cerebral ganglia to both the pleural and pedal ganglia (Fig. 4; Table 1). However, significant transport of several previously unidentified peptides to the pedal and abdominal ganglia was also observed. Transport of these peptides to the abdominal ganglia was particularly prominent. Peak 1 has a similar retention time to many identified peptides $\left(\mathrm{SCP}_{\mathrm{A}}\right.$, myomodulin, buccalin, and Pep) with TFA as a counterion. RP-HPLC with HFBA as a counterion indicates that the predominant component of Peak 1 was the same in the abdominal and pedal ganglia and that it had a retention time shorter than any of these identified peptides (Fig. 5). The retention time of these synthetic peptides increased as the peptides become more basic. Thus, the predominant component of Peak 1 is likely to be a relatively acidic peptide. A small peak of labeled Pep was also found in Peak 1 from the pedal ganglia. Similar quantities of labeled Pep were also found in control experiments carried out in colchicine so the labeled Pep probably does not reflect transport of Pep but synthesis endogenous to the pedal ganglia using ${ }^{35} \mathrm{~S}$-methionine which had diffused from the cerebral ganglia or leaked into the outer chamber.

Peak 2 was also found in the abdominal and pedal ganglia; however, the composition of this peak proved to be different in each ganglia. RP-HPLC with HFBA revealed a small but reproducible difference in retention times between Peak 2 from the 2 ganglia (data not shown). Because these differences in retention time were small, this peak was also analyzed by IEHPLC (Fig. 6). In this system, Peak 2 from the abdominal ganglia eluted predominantly in a single highly retained peak with a retention time similar to $\mathrm{SCP}_{\mathrm{A}}$, a very basic peptide
(Lloyd et al., 1987b). Meanwhile Peak 2 from the pedal ganglia resolved into 2 peaks, a small one with a shorter retention time and a large peak with a retention time slightly longer than the predominant peak from the abdominal ganglia. These differences were consistently observed $(n=3)$ and were not due to run-to-run variability because added synthetic peptides (i.e., $\mathrm{SCP}_{\mathrm{A}}$ ) monitored by absorbance had identical retention times in each run. Thus, Peak 2 was transported from the cerebral ganglia to the abdominal and pedal ganglia, but the composition was different for each target ganglia.

Peak 3 was also transported to both the pedal and abdominal ganglia. Further analyses of this peak by both RP-HPLC with HFBA as a counterion (Fig. 5) and IE-HPLC (data not shown) indicate that it was composed predominantly of a single basic peptide species with identical chromatographic properties in each ganglia.

The amount of labeled peptides extracted from the abdominal ganglia probably represents underestimates of the total amount transported to the ganglia. In 3 experiments in which transport from the cerebral ganglia to the abdominal ganglia was analyzed, the pleural-abdominal connectives were also extracted and run on HPLC. The same peptide profiles with nearly the same activity as in the abdominal ganglion $(0.87 \pm 0.38$; SD for 3 peptide peaks from each of 3 preparations) were observed in the connectives. These labeled peptides presumably represent material that would have eventually been transported into the abdominal ganglion. Although not analyzed in this study, it appears likely that peptides transported from the abdominal ganglia along the connectives would also represent underestimates of the total transport.

\section{Transport from the pedal-pleural ganglia}

Although the pleural and pedal ganglia could be dissected and analyzed separately as targets for transport, they were too closely apposed to be independently labeled (Fig. 1). Peptides were observed to be transported to the abdominal and cerebral ganglia but not the buccal ganglia (Table 1). FMRFamide was the predominant peptide transported to the abdominal ganglion, while FMRFamide and Pep were the predominant peptides transported to the cerebral ganglia (Fig. 7). It is very likely that the transported Pep was from the pedal ganglia as the pleural ganglia have nearly undetectable rates of Pep synthesis (Lloyd and Connolly, 1989). 

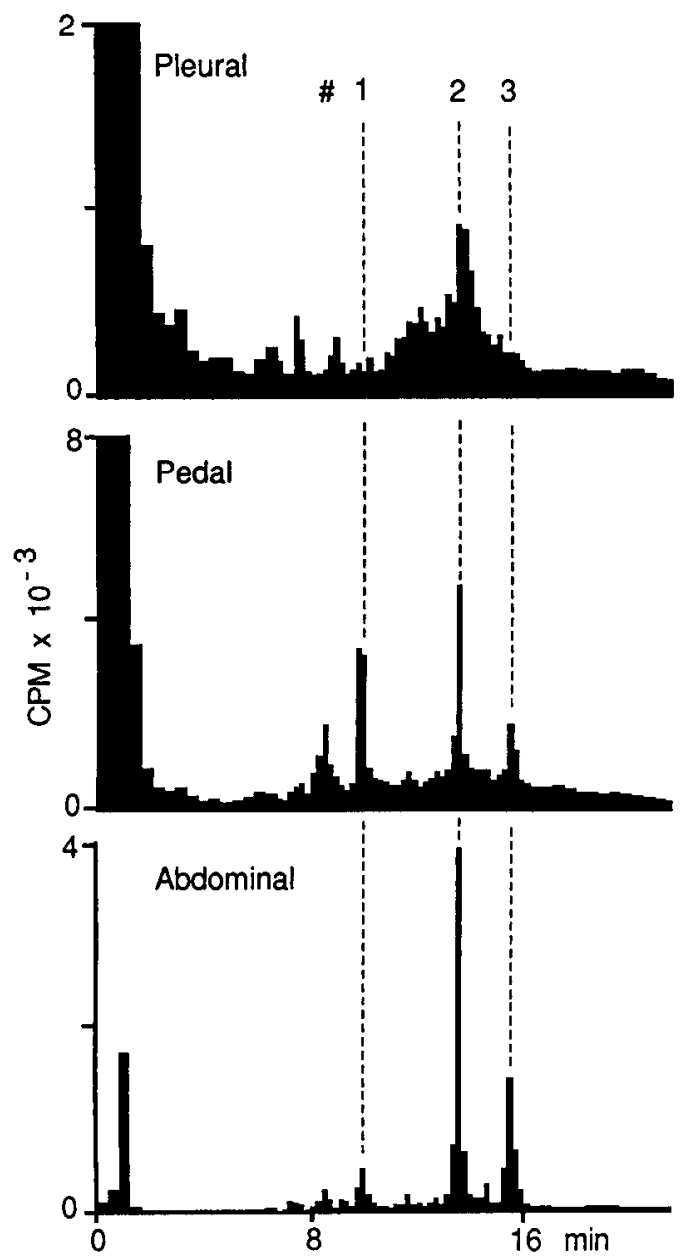

Figure 4. Transport of labeled peptides from the cerebral ganglia to the pleural, pedal, and abdominal ganglia. Control transport experiments were run under identical conditions except $10 \mathrm{~mm}$ colchicine was added to both the inner and outer chambers. The only discrete peptide peak in the controls was Pep in the pedal ganglia $(660 \mathrm{cpm})$, so these runs were omitted for clarity. Aliquots of indicated peaks were analyzed further by RP-HPLC with HFBA and IE-HPLC(Figs. 5, 6). These results are representative of an additional 7 experiments.

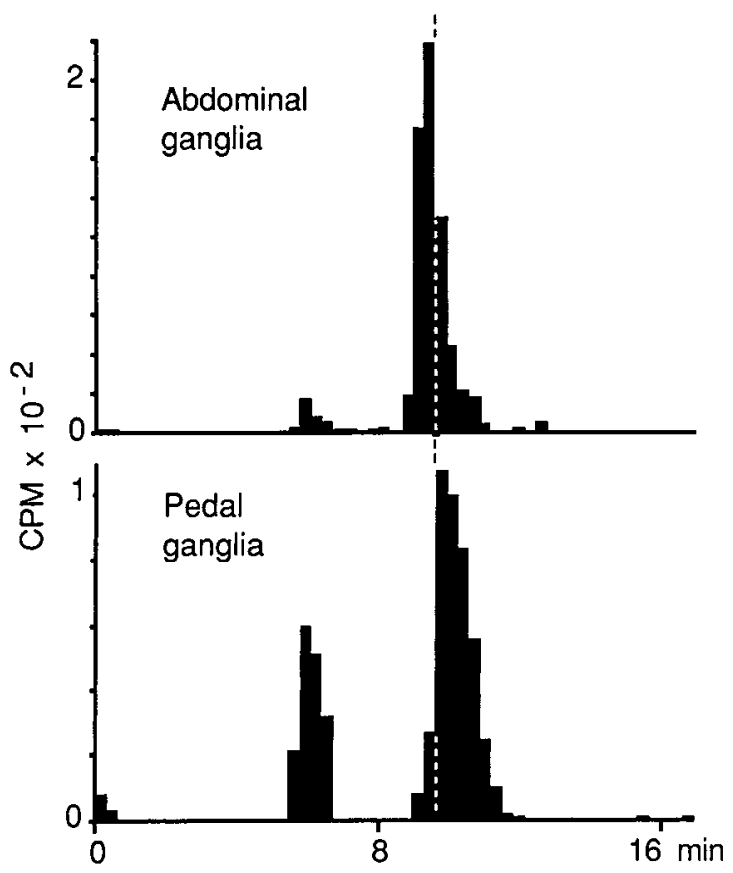

Figure 6. IE-HPLC of aliquots from Peak 2 from the abdominal and pedal ganglia (Fig. 4). Note that Peak 2 from the pedal ganglia elutes as 2 peaks and that the larger of these peaks elutes later than the predominant peak from the abdominal ganglia. These results are representative of 2 additional experiments. The gradient used in these experiments was designed to resolve very basic peptides and most components of the ganglia extracts were not retained at all by the column.

\section{Discussion}

The first objective of this study was to identify already characterized peptides that may play important roles in interganglionic communication. In this category, the major peptide was FMRFamide which was transported in large amounts between specific ganglia and transported in lesser quantities between the majority of the ganglia (Table 1). Myomodulin and Pep were also transported in significant quantities but only between a few
Peak \#1

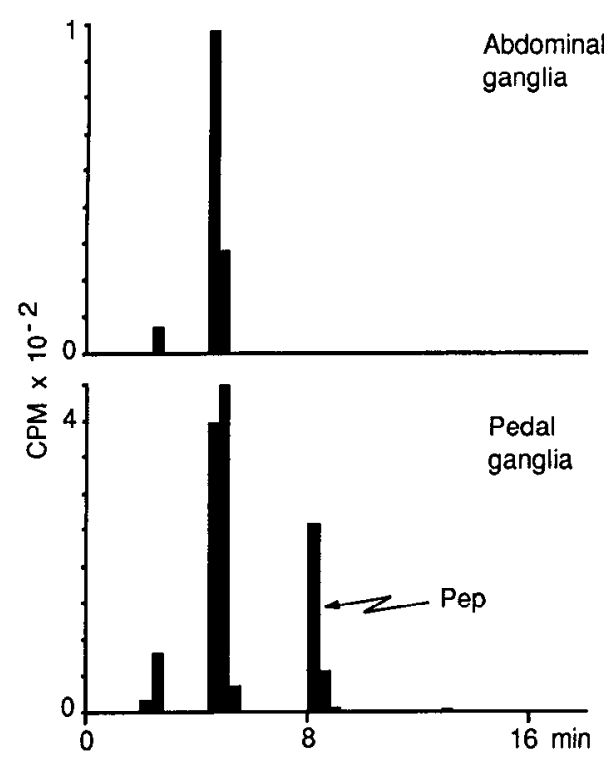

Peak \#3



Figure 5. RP-HPLC with HFBA as a counterion of aliquots from Peaks 1 and 3 from Figure 4. The compositions of each peak appear very similar in each ganglia with the exception that Peak 1 from the pedal ganglia also contains Pep. It is likely that this Pep was synthesized in the pedal ganglia itself as the colchicine control pedal ganglia also synthesized Pep (see Fig. 4). Peak 3 was also run on IE-HPLC, where it also eluted as a single peptide species with identical retention time in each ganglia. These results are representative of 2 additional experiments. 

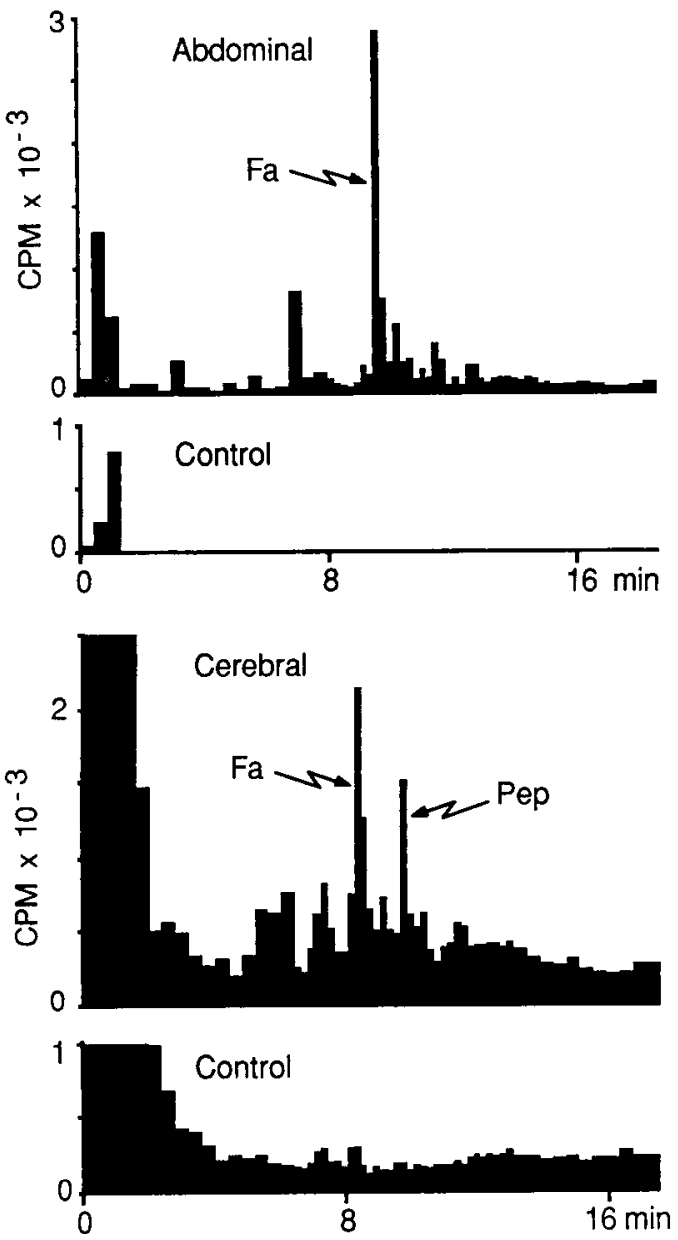

Figure 7. Transport of labeled peptides from the pedal-pleural ganglia to the abdominal and cerebral ganglia. These results are from different experiments with the abdominal-plcural connective intact for the abdominal ganglia and the pedal-pleural-cerebral connectives intact for the cerebral ganglia (see Fig. 1). Aliquots of peaks were run on RPHPLC with HFBA as counterion and $80 \%$ of the cpm in the peak marked $\mathrm{Fa}$ in the abdominal ganglia eluted with synthetic FMRFamide. This value was $77 \%$ for the Fa peak in the cerebral ganglia, while $73 \%$ of the $\mathrm{cpm}$ in the Pep peak eluted with synthetic Pep. These results are representative of an additional 4 experiments. The difference in the retention times of both synthetic FMRFamide and labeled Fa peaks in these 2 experiments was due to a column change.

ganglia. Finally, small quantities of the SCPs were observed to be transported from the buccal to the cerebral ganglia. There is considerable evidence that FMRFamide, the SCPs, Pep, and myomodulin are widely distributed neuropeptides with a number of central and peripheral physiological actions (Lehman et al., 1984; Brown et al., 1985; Lloyd et al., 1985; 1987a, 1988; Shaefer et al., 1985; Lloyd, 1986; Cropper et al., 1987b; Pearson and Lloyd, 1989). In several cases, these peptides have wellestablished roles as modulatory transmitters (Abrams et al., 1984; I loyd et al., 1984; Belardetti et al., 1987; Mackey et al., 1987; Cropper et al., 1987b). In addition, FMRFamide and the SCPs have been localized to dense-core synaptic vesicles (Kreiner et al., 1986; Reed et al., 1988) and the SCPs are released by stimulation of identified neurons in culture (Lloyd et al., 1986). FMRFamide, myomodulin, and the SCPs are also transported from buccal ganglia to buccal muscle, and individual neurons that synthesize these peptides in the buccal ganglia have been identified (Cropper et al., 1987a, b; Lloyd, 1988).

The second goal was to identify new peptide transmitter candidates that may also play important roles in interganglionic communication. Several peptides transported from the buccal to the cerebral ganglia and from the cerebral to the pedal and abdominal ganglia fall into this category (Table 1). Peptides transported from the cerebral ganglia may be particularly important in behavioral regulation as these ganglia receive input from a number of sensory structures and appear to be involved in the higher-order control of many behaviors, including locomotion and both appetitive and consummatory aspects of feeding (Kupfermann, 1974; Kandel, 1979; Fredman and JahanParwar, 1983).

These results do not rulc out the possibility that there werc other methionine-containing neuropeptides transported between ganglia. Peaks with low activity were observed in many experiments, but it was not possible to determine whether these were fragments of other transported peptides, peptides synthesized in the ganglia themselves, or neuropeptides transported from the labeled ganglia at low levels. Finally, although most of the neuropeptides characterized from Aplysia do contain methionine residues, many small peptides do not, and these peptides would not have been observed in this study.

It would be useful to estimate the magnitude of the observed transport in terms of actual peptide quantities. A very rough estimate can be made based on previous results from nearly identical experiments measuring transport between the buccal ganglia and buccal muscles (Lloyd, 1988). The estimates are specifically directed towards the SCPs because the amounts of the SCPs in terminals in buccal muscle have been accurately measured by bioassay (Lloyd et al., 1984). In these experiments, transport of approximately $10^{3} \mathrm{cpm}$ of a peptide containing a single methionine residue corresponds to a muscle content of 1 pmol of that peptide. If a similar relationship holds for the peptides transported between ganglia, the maximum transport observed in this study would correspond to $10 \mathrm{pmol}$ peptide. This would be a significant proportion of the total peptide content of some ganglia. For example, the entire Aplysia CNS contains about 100 pmol FMRFamide or the SCPs (Lehman et al., 1984; Lloyd et al., 1985).

A quantitative comparison of peptide transport is not possible due, in some cases, to an unknown number of methionine residues in a peptide and to large differences in distances between ganglia, ranging from a few millimeters between the cerebral, pleural, and pedal ganglia to many centimeters for the abdominal connectives (Fig. 1). However, in some instances, the greatest amount of labeled peptide was transported the longer distances. Examples of this include the peptides transported in both directions between the cerebral and buccal ganglia and FMRFamide transported from the abdominal ganglia and several unidentified peptides transported from the cerebral to the abdominal ganglia.

The question remains of whether the uncharacterized transported peptides serve a transmitterlike role. There are several reasons to believe that this is indeed the case for many of the peptides. First, as decribed above, several of the transported peptides have been identified as characterized neuropeptides previously shown to have transmitterlike actions in Aplysia. Second, the nature of the transport is specific to both the source ganglia incubated with label and its target ganglia. It is possible that the peaks could be processed fragments of precursors that 
do not have transmitterlike actions such as the C-peptide in insulin-secreting cells or the neurophysins in vasopressin- and oxytocin-secreting neurons (Brownstein et al., 1980; Docherty and Steiner, 1982). However, similar procedures carried out using peripheral targets have consistently revealed peptides with transmitterlike roles (Lloyd, 1988; Pearson and Lloyd, 1989). Several of the more prominent of the newly identified peptides have been targetcd for furthcr investigation beginning with purification and sequence analyses.

The final objective of this study was to lay the groundwork for the identification of peptidergic synapses. By combining retrograde filing of axons in the connectives with immunocytological procedures, it should be possible to identify peptidergic neurons in the source ganglia that send axons via the connective to target ganglia. These neurons will immediately become candidates for presynaptic peptidergic neurons that form synapses in target ganglia. Similar procedures have recently been used to demonstrate that only a single neuron in the left pleural ganglion was both FMRFamide-immunoreactive and had an axon in the left pleural-abdominal connective (Mackey et al., 1987). The powerful cellular procedures developed to study synaptic transmission in Aplysia could then be applied to peptidergic synapses.

\section{References}

Abrams, T. W., V. F. Castellucci, J. S. Camardo, E. R. Kandel, and P. E. Lloyd (1984) Two endogenous ncuropeptides modulate the gill and siphon withdrawal reflex in Aplysia by presynaptic facilitation involving cAMP dependent closure of a serotonin-sensitive potassium channel. Proc. Natl. Acad. Sci. USA 81: 7956-7960.

Belardetti, F., E. R. Kandel, and S. A. Siegelbaum (1987) Neuronal inhibition by the peptide FMRFamide involves opening of the $\mathrm{S} \mathrm{K}^{+}$ channels. Nature 325: 153-156.

Brown, R. O., D. Gusman, A. I. Basbaum, and E. Mayeri (1985) Identification of Aplysia neurons containing immunoreactive FMRFamide. Neuropeptides 6: 517-526.

Brownstein, M. J., J. T. Russell, and H. Gainer (1980) Synthesis, transport and release of posterior pituitary hormones. Science 207: 373-378.

Cropper, E. C., P. E. Lloyd, W. Reed, R. Tenenbaum, I. Kupfermann, and K. R. Weiss (1987a) Multiple neuropeptides in cholinergic motor neurons of Aplysia: Evidence for modulation intrinsic to the motor circuit. Proc. Natl. Acad. Sci USA 84: 3486-3490.

Cropper, E. C., R. Tenenbaum, M. A. Gawinowicz Kolks, I. Kupfermann, and K. R. Weiss (1987b) Myomodulin: A bioactive neuropeptide present in an identified cholinergic buccal motor neuron of Aplysia. Proc. Natl. Acad. Sci. USA 84: 5483-5486.

Cropper, E. C., M. W. Miller, R. Tenenbaum, M. A. Gawinowicz Kolks, I. Kupfermann, and K. R. Weiss (1988) Structure and action of buccalin: A modulatory neuropeptide localized to an identified small cardioactive peptide-containing cholinergic motor neuron of Aplysia californica. Proc. Natl. Acad. Sci. USA 85: 6177-6181.

Docherty, K., and D. F. Steiner (1982) Post-translational proteolysis in polypeptide hormone biosynthesis. Annu. Rev. Physiol. 44: 625638.

Fredman, S. M., and B. Jahan-Parwar (1983) Command neurons for locomotion in Aplysia. J. Neurophysiol. 49: 1092-1117.

Kandel, E. R. (1979) Behavioral Biology of Aplysia, pp. 123-127, W. H. Freeman, San Francisco.

Kreiner, T., W. Sossin, and R. H. Scheller (1986) Localization of Aplysia neurosecretory peptides to multiple populations of dense core vesicles. J. Cell Biol. 102: 769-782.

Kupfermann, I. (1974) Dissociation of the appetitive and consummatory phases of feeding behavior in Aplysia: A lesion study. Behav. Biol. 10: 89-97.
Lehman, H. K., D. A. Price, and M. J. Greenberg (1984) The FRFamide-like peptide of Aplysia is FMRFamide. Biol. Bull. 167:460466.

Lloyd, P. E. (1986) The small cardioactive peptides: A class of modulatory neuropeptides in Aplysia. Trends Neurosci. 9: 428-431.

Lloyd, P. E. (1988) Fast axonal transport of modulatory neuropeptides from central ganglia to components of the feeding system in Aplysia. J. Neurosci. 8: 3507-3514.

Lloyd, P. E., and C. M. Connolly (1989) Sequence of pedal peptideA novel neuropeptide from the central nervous system of Aplysia. J. Neurosci. 9: 312-317.

Lloyd, P. E., I. Kupfermann, and K. R. Weiss (1984) Evidence for parallel actions of a molluscan peptide $\left(\mathrm{SCP}_{\mathrm{B}}\right)$ and serotonin in mediating arousal in Aplysia. Proc. Natl. Acad. Sci. USA. 81: 29342937.

Lloyd, P. E., A. C. Mahon, K. Kupfermann, J. L. Cohen, R. H. Scheller, and K. R. Weiss (1985) Biochemical and immunocytological localization of molluscan small cardioactive peptides (SCPs) in the nervous system of Aplysia californica. J. Neurosci. 5: 1851-1861.

Lloyd, P. E., S. Schacher, I. Kupfermann, and K. R. Weiss (1986) Calcium-dependent release of neuropeptides during intracellular stimulation of single identified Aplysia neurons in culture. Proc. Natl. Acad. Sci. USA 83: 9794-9798.

Lloyd, P. E., M. Frankfurt, P. Stevens, I. Kupfermann, and K. R. Weiss (1987a) Biochemical and immunocytological localization of the neuropeptides $\mathrm{SCP}_{\mathrm{A}}, \mathrm{SCP}_{\mathrm{B}}$, and FMRFamide to neurons involved in the regulation of feeding in Aplysia. J. Neurosci. 7: 1123-1132.

Lloyd, P. E., I. Kupfermann, and K. R. Weiss (1987b) The sequence of small cardioactive peptide A: A second member of a class of neuropeptides in Aplysia. Peptides 8: 179-184.

Lloyd, P. E., I. Kupfermann, and K. R. Weiss (1988) Central peptidergic neurons regulate gut motilitiy in Aplysia. J. Neurophysiol. 59: 1613-1626.

Mackey, S. L., D. L. Glanzman, S. A. Small, A. M. Dyke, E. R. Kandel, and R. D. Hawkins (1987) Tail shock produces inhibition as well as sensitization of the siphon-withdrawal reflex of Aplysia: Possible behavioral role for presynaptic inhibition mediated by the peptide

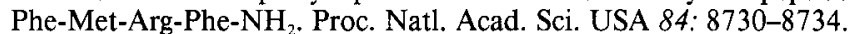

Mahon, A. C., P. E. Lloyd, K. R. Weiss, I. Kupfermann, and R. H. Scheller (1985) The small cardioactive peptides A and B of Aplysia are derived from a common precursor molecule. Proc. Natl. Acad. Sci. USA 82: 3925-3929.

Morris, H. R., M. Panico, A. Karplus, P. E. Lloyd, and B. Riniker (1982) Elucidation by FAB-MS of the structure of a new cardioactive peptide from Aplysia. Nature 300: 643-645.

Pcarson, W. L., and P. E. Lloyd (1989) Immunocytological localization of pedal peptide in the central nervous system and periphery of $\mathrm{Aply}$ sia. J. Neurosci. 9: 318-325.

Price, D. A., and M. J. Greenberg (1977) Structure of a molluscan cardioexcitatory neuropeptide. Science 197:670-671.

Rayport, S. G., and E. R. Kandel (1980) Developmental modulation of an identified electrical synapse: Functional uncoupling. J. Neurophysiol. 44: 555-567.

Reed, W., K. R. Weiss, P. E. Lloyd, I. Kupfermann, M. Chen, and C. H. Bailey (1988) Association of neuroactive peptides with the protein secretory pathway in identifed neurons of Aplysia californica: Immunolocalization of $S C P_{A}$ and $S C P_{B}$ to the contents of dense-core vesicles and the Trans face of the Golgi appartus. J. Comp. Neurol. 272: 358-369.

Richmond, J. E., A. G. M. Bulloch, and K. Lukowiak (1986) Peptidergic modulation of a neuromuscular junction in Aplysia: Bioactivity and immunocytochemistry. Brain Res. 370: 159-164.

Schaefer, M., M. R. Picciotto, T. Kreiner, R.-R. Kaldany, R. Taussig, and R. H. Scheller (1985) Aplysia neurons express a gene encoding multiple FMRFamide neuropeptides. Cell 41: 457-467.

Weiss, K. R., P. E. Lloyd, E. C. Cropper, M. Frankfurt, and I. Kupfermann (1986) FMRFamide is present in the ARC muscle of Aplysia and depresses its contractions. Soc. Neurosci. Abstr. 12: 947. 